\title{
Foodborne Outbreak, Meknes, Morocco, June 2017: What We Need to Learn
}

Touria Essayagh ${ }^{1,2^{*}}$, Meriem Essayagh ${ }^{3}$, Abderrahman EI Rhaffouli $^{2}$, Mohamed Khouchoua ${ }^{2}$, Sanah Essayagh ${ }^{4}$ and Asmae Khattabi $^{1}$

${ }^{1}$ National School of Public Health, FETP, Rabat, Morocco

${ }^{2}$ Prefectural Epidemiology Cell, Ministry of Health, Meknès, Morocco

${ }^{3}$ Univesity of Mohamed V, Rabat, Morocco

${ }^{4}$ University Hassan Ist, Faculty of Sciences and Techniques, Settat, Morocco

*Corresponding author: Touria Essayagh, National School of Public Health, FETP, Rabat, Morocco, Tel: +212-669-679-966; E-mail: essayagh.toula@gmail.com Received date: July 02, 2017; Accepted date: July 19, 2017; Published date: July 28, 2017

Copyright: $\odot 2017$ Essayagh T, et al. This is an open-access article distributed under the terms of the Creative Commons Attribution License, which permits unrestricted use, distribution, and reproduction in any medium, provided the original author and source are credited.

\begin{abstract}
Introduction: A Foodborne outbreaks remain a public health threat in Morocco that require compulsory reporting and epidemiological surveys to halt any risk of epidemics. We report a foodoutbreak that occurred in Meknes on the 10th of June 2017. We assessed its extent, determined its source and enforced preventive measures.

Methods: We performed a retrospective cohort study among the guests of the dinner to identify risk factors associated with the illness. Data were analyzed using Epi Info version 7. Association between assumed risk factors and intoxication was estimated using the relative risk (RR) and its $95 \%$ confidence interval. Percentages as well as p-values were determined using Fisher's exact test.

Results: Among the 15 guests, 9 cases were ill with an attack rate of $60 \%$. The mean age was $39 \pm 11.9$ years with a male/female sex ratio of 0.28 . The mean incubation period was $3 \pm 3 \mathrm{~h} 30$. The symptoms reported were vomiting $(88.9 \%)$, dizziness $(88.9 \%)$, abdominal cramping $(44.4 \%)$, headache $(44.4 \%)$ and fatigue $(33.3 \%)$. All cases had a positive outcome. Chicken consumption was associated with the intoxication $(p=0.04)$. The cook did not respect hand hygiene rules.

Conclusion: Although laboratory results were negative for microbiological and environmental germs, clinical signs suggest that the probable cause of intoxication are enterotoxins secreted by Staphylococcus aureus commonly found when hygiene is lacking and food storage is deficient. We recommend reinforcing public awareness on the importance of respecting the cold chain and the basic rules of hygiene.

Practical application: Our results show Defrosting the chicken for 7 hours without respecting the cold chain could be the cause of the proliferation of staphylococci and the production of enterotoxins. Some recommendations can be made following this survey, in particular: raising public awareness of the importance of respecting the cold chain and the rules of food hygiene.
\end{abstract}

Keywords: Foodborne outbreak; Enterotoxins; Staphylococcus aureus

\section{Introduction}

Foodborne outbreaks (FBOs) linked to food consumption at home, in restaurants and other public venues remain a relevant issue in terms of public health and economic impact. In Morocco, the FBOs are compulsory reporting and investigations are to be carried out.

The FBOs due to bacterial toxins are one of the most common diseases connected with food illness [1]. In the European Union, in 2015, bacterial toxins were responsible for $19.5 \%$ of all FBOs and 16 Member States (MS) reported 434 foodborne outbreaks caused by staphylococcal toxins.

Staphylococcus aureus frequently colonize the skin and mucosa of human beings. It's present on $88 \%$ of the hands and $48 \%$ of the aprons of food handlers working in the delicatessen sections of a retail store [2]. These data show that human contamination with enterotoxigenic strains during food preparation and processing plays an important role as a source of food contamination.

In this study, we describe a FBO that occurred at a familial dinner to estimate the magnitude of the outbreak, to identify the vehicle of contamination and to prevent further cases. The outbreak on 10th June 2017, among the 15 individuals who had participated in a familal dinner in Meknès 9 persons fell ill with symptoms including vomiting, diarrhoea and abdominal cramping. they people were transported to hospital. This report summarises the epidemiological and microbiological investigations into the cause of the outbreak.

\section{Materials and Methods}

\section{Field work preparation}

Field epidemiologists developed an operational case definition based on the common clinical and epidemiological signs identified in the confirmatory epidemic survey. A data collection tool was designed 
Page 2 of 4

to collect the epidemiological data to identify the risk factors associated with intoxication. The draft of the data tool designed was peer reviewed before being adopted [3]

\section{Case identification}

The epidemiological investigation was conducted June 10, 2017. It concerned a household in Meknes. An interrogation with the patients was carried out. A case was defined as any person who presented the following symptoms: Dizziness, nausea, abdominal cramping, headache, excessive thirst or fever greater than $38^{\circ} \mathrm{C}$ within 24 hours after had eating the dinner on June 10, 2017.

An adapted, closedended questionnaire was used to collect data on the: i) demographic data, ii) clinicals symptoms, iii) food items consumed at dinner, iv) date and time of consumption, v) date and time of symptoms, vi) and outcome of patient [4-6].

The data were entered and analyzed on Epi Info version 7. The epidemic curve was performed by Excel version 7 and the attack rate was calculated. The epidemiological description of the data was done in terms of time of place and person.

\section{Analytical epidemiology}

We performed a retrospective cohort study among the guests of the familial dinner to identify risk factors associated with illness. The interview was conducted with all the people had familal dinner.

The data were entered and analyzed on Epi Info version 7. A bivaried analysis was performed to determine the factors associated with intoxication and to determine the variables to be included in the multivariate analysis. The association between each assumed risk factor and intoxication was estimated using relative risk (RR) and 95\% confidence interval. As well as the p-value values using Fisher's exact test [7].

\section{Microbiological investigation}

The remains of the chicken, tomato sauce and green olives were available for microbiological analysis. Food specimen were stored at $4^{\circ} \mathrm{C}$ and processed for bacteriological analysis within 24 hours. Samples were tested for several enteric pathogens (B. cereus, Campylobacter, Clostridium perfringens, Enterobacteriaceae, E.coli, Listeria monocytogenes, Salmonella spp., Staphylococci). An enrichment medium sodium selinite was used to isolate salmonellae.

Faecal specimens were collected in $22 \%$ of cases within 10 hours of symptom onset. Part of the specimens was processed to detect Salmonella spp., Shigella, Campylobacter, Vibrios and other enteropathogens using the enrichment medium sodium, Salmonella and Shigella medium and CLED medium (Cystine Lactose Electrolyte Deficient). No test for staphylococcal enterotoxins was performed [8].

\section{Environmental investigation and public health response}

We interviewed the food handler regarding food purchase, preparation process, storage and cleaning procedures. The list of food items served during dinner has been established (Couscous, Tajine of Chicken, Green Olives, Tomato Sauce, Melon, Bread and Coca Cola)

\section{Ethics statements}

Ethical approval was not required for this study because the main of the epidemiological investigation was to determine the extent of the poisoning, its source, its characteristics and to control public health threat. All participants had given their verbal informal consent. Laboratory tests were performed following routine diagnosis and treatment procedures $[9,10]$.

\section{Results and Discussion}

\section{Description of the outbreak}

Nine of the 15 guests were identified (attack rate of 60\%). The average age of the study population was $39 \pm 11.9$ years with a female sex ratio of 0.28 . The mean incubation period was $3 \pm 3 \mathrm{~h} 30 \mathrm{a} . \mathrm{m}$. Cases began to occur on June $10^{\text {th }}$ at $20^{\prime}$ clock and the peaked on the same day at 2:30 a.m with 3 cases with last case at 12:00 p.m on the same day (Figure 1).

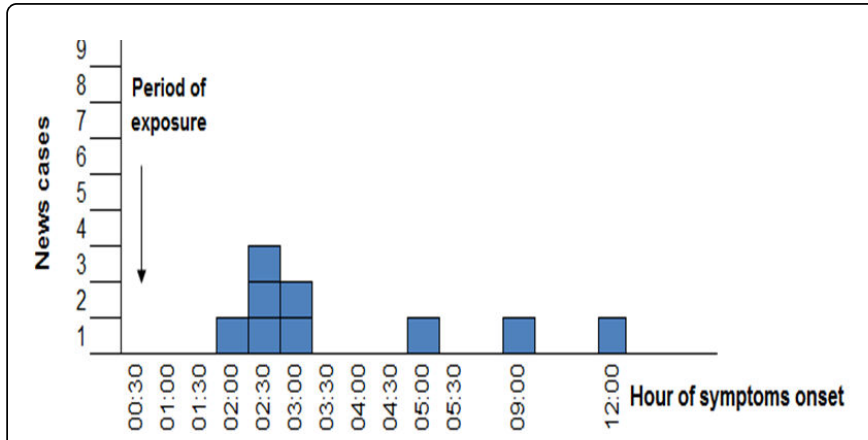

Figure 1: Epidemic curve of collective chicken food poisoning, 10 June 2017, Mansour, Meknès, Morocco.

The most frequently reported symptoms were vomiting $(88.9 \%)$, dizziness (88.9\%), abdominal cramping (44.4\%), headache $(44.4 \%)$ and fatigue $(33.3 \%)$ (Table 1$)$.

\begin{tabular}{|l|l|}
\hline Symptoms & Frequency (\%) \\
\hline Vomiting & $8(88.9)$ \\
\hline Dizziness & $8(88.9)$ \\
\hline Abdominal cramping & $4(44.4)$ \\
\hline Headache & $4(44.4)$ \\
\hline Fatigue & $3(33.3)$ \\
\hline Tachycardia & $2(22.2)$ \\
\hline Fever $>37^{\circ} \mathrm{C}$ & $1(11.1)$ \\
\hline Excessive thirst & $1(11.1)$ \\
\hline Nausea & $1(11.1)$ \\
\hline
\end{tabular}

Table 1: Distribution of symptoms of collective food poisoning, Meknes, Morocco, June 2017. 


\section{Cohort study}

Food specific attack rate for tomato sauce was $83.3 \%$, while that of green olives and tajine of chicken was $75.0 \%$ each. People who had consumed couscous were 2 times more likely to become (CI 95\%; $(0.38-10.4))$. Only tajine of chicken was significantly associated with the occurrence of collective food poisoning $(\mathrm{p}=0.04)$ (Table 2).

\begin{tabular}{|l|l|l|l|l|l|l|l|l|l|l|}
\hline \multicolumn{9}{|c|}{ Incidence of disease } \\
\hline & Among exposed & \multicolumn{2}{l|}{ Among unexposed } & & \\
\hline & N & Total & $\%$ & N & Total & $\%$ & RR & $95 \%$ CI & p-value \\
\hline Couscous & 8 & 12 & 66.7 & 1 & 3 & 33.3 & 2.0 & $(0.4-10.4)$ & 0.52 \\
\hline Tajine of kitchen & 9 & 12 & 75.0 & 0 & 3 & 0.0 & -- & -- & 0.04 \\
\hline Melon & 9 & 13 & 69.2 & 0 & 2 & 0.0 & -- & -- & 0.14 \\
\hline Green olive & 3 & 4 & 75.0 & 8 & 11 & 72.7 & 1.0 & $(0.5-2.0)$ & 1.00 \\
\hline Tomato sauce & 5 & 6 & 83.3 & 7 & 9 & 77.8 & 1.1 & $(0.6-1.8)$ & 1.00 \\
\hline Coca Cola & 9 & 13 & 69.2 & 0 & 2 & 0.0 & -- & -- & 0.14 \\
\hline Bread & 9 & 13 & 69.2 & 0 & 2 & 0.0 & -- & -- & 0.14 \\
\hline
\end{tabular}

Table 2: Incidence of Staphylococcus aureus infection according to selected characteristics, retrospective cohort study. Mansour, Meknes Morocco, 10 June 2017.

\section{Environnemental results}

The interview conducted with food handler the dinner showed that the hands were not washed with soap before handling food. However, he reported having handled the foods provided on a cleaned surface with clean utensils. The tajine of chicken was cooked previously thawed (7 hours) at room temperature. None wounds or boils were found. The tajine of chiken prepared for dinner has remained more than 12 hours at room temperature of the kitchen. Indeed, the tajine was cooked at 12:00 p.m of June 09, 2017 and consumed at midnight thirty. Before consumption, the tajine was slightly warmed [11-13].

\section{Microbiological results}

The results of the food and stool specimen from the patients were all negative. Staphylococcal poisoning, particularly Staphylococcus aureus, is one of the major causes of food-borne bacterial infections worldwide. They are caused by the enterotoxins produced by these bacteria in foods such as meats, eggs and ice creams [3]. These enterotoxins cause rapid onset of nausea, vomiting and abdominal cramps with the presence or absence of diarrhea.

Depending on the immunity of persons and the amount of enterotoxin ingested, the average incubation period is 3 hours with a minimum duration of 30 minutes and a maximum duration of 8 hours [4]. In our study, all the clinical symptoms and the average period of incubation were in favor of a collective food poisoning due to the enterotoxins produced by the $S$. aureus, however the biological specimens obtained from the patients and the foodstuffs didn't allow the isolation of the germ, which could probably be explained by the destruction of the bacterium during the refrigeration of the rest of the food. In this epidemic, the risk factor associated with intoxication was chicken tagine. Defrosting the chicken for 7 hours without respecting the cold chain could be the cause of the proliferation of staphylococci and the production of enterotoxins. The subsequent warming of the chicken did not destroy the thermostable toxin.
There were some limitations to our study, including the nonbiological confirmation following the non-isolation of the germ. In the present investigation, the alert was reported early at the CPE in Meknes and allowed to set up the first actions of case management and seizure of the dishes available the same day of the poisoning. Active case finding was conducted. A questionnaire administered face-to-face the same day made it possible to limit the biases of response and memory.

\section{Conclusion and Recommendation}

This investigation made it possible to confirm the occurrence of a TIAC on June 10th 2017 with 9 cases belonging to the same family.

The source of contamination guided by clinical signs would be in favor of poor preservation of food. Some recommendations can be made following this survey, in particular raising public awareness of the importance of respecting the cold chain and the rules of food hygiene.

\section{Acknowledgments}

We thank the Health Delegation of Meknes and the team of the Microbiology Laboratory of the Prefectural Hospital of Meknes for their collaboration.

\section{Author Contributions}

Touria Essayagh: Designed the study, collected data, analyzed, interpreted the results and drafted the manuscript; Abderrahman El Rhaffouli: Designed the study and collected data; Mohamed Khouchoua: Drafted the manuscript; Sanah Essayagh: Analyzed, interpreted the results and drafted the manuscript; Asmae Khattabi: Drafted the manuscript. 
Citation: $\quad$ Essayagh T, Essayagh M, Rhaffouli AE, Khouchoua M, Essayagh S, et al. (2017) Foodborne Outbreak, Meknes, Morocco, June 2017: What We Need to Learn. J Trop Dis 5: 241. doi:10.4172/2329-891X.1000241

Page 4 of 4

\section{References}

1. EFSA, ECDC (2016) The European Union summary report on trends and sources of zoonoses, zoonotic agents and foodborne outbreaks in 2015 EFSA J 14: 231-238.

2. Lues JFR, Van TI (2007) The occurrence of indicator bacteria on hands and aprons of food handlers in the delicatessen sections of a retail group. Food Control 18: 326-332.

3. Fetsch A, Contzen M, Hartelt K (2014) Staphylococcus aureus foodpoisoning outbreak associated with the consumption of ice-cream. Int J Food Microbiol 187: 1-6.

4. Loir Y, Baron F, Gautier M (2013) Staphylococcus aureus and food poisoning. Genet Mol Res 2(1): 63-76.

5. Mead PA, Slutsker L, Dietz V (1999) Food-related illness and death in the United States. Emerg Infect Dis 5: 607-625.

6. Duff SB, Scott E, Malfios MM (2003) Cost effectiveness of a targeted disinfection program in household kitchens to prevent foodborne illness in the United States, Canada and the United Kingdom. J Food Protect 66: 2103-2115.

7. Kaferstein FK (2003) Actions to reverse the upward curve of foodborne illness. Food Control 14: 101-109.

8. Kaferstein F (2003) Foodborne disease in developing countries: Aetiology, epidemiology and strategies for prevention. Int J Environ Health Res 13: 161-168.

9. Coker AO, Isokpehi RD, Thomas BN, Amisu KO (2002) Human camylobacteriosis in developing countries. Emerg Infect Dis 8: 237-243.

10. Scott E (1996) A review of foodborne disease and other hygiene issues in the home. J Appl Bacteriol 80: 5-9.

11. Mead PA, Finelli L, Lambert FMA (1997) Risk factors for sporadic infection with Escherichia coli O157: H7. Arch Intern Med 157: 204-248.

12. Jay L, Comar D, Govenlock LD (1999) A video study of Australian domestic food-handling practices. J Food Protect 62: 1285-1296.

13. https://www.canada.ca/en/health-canada.html 